
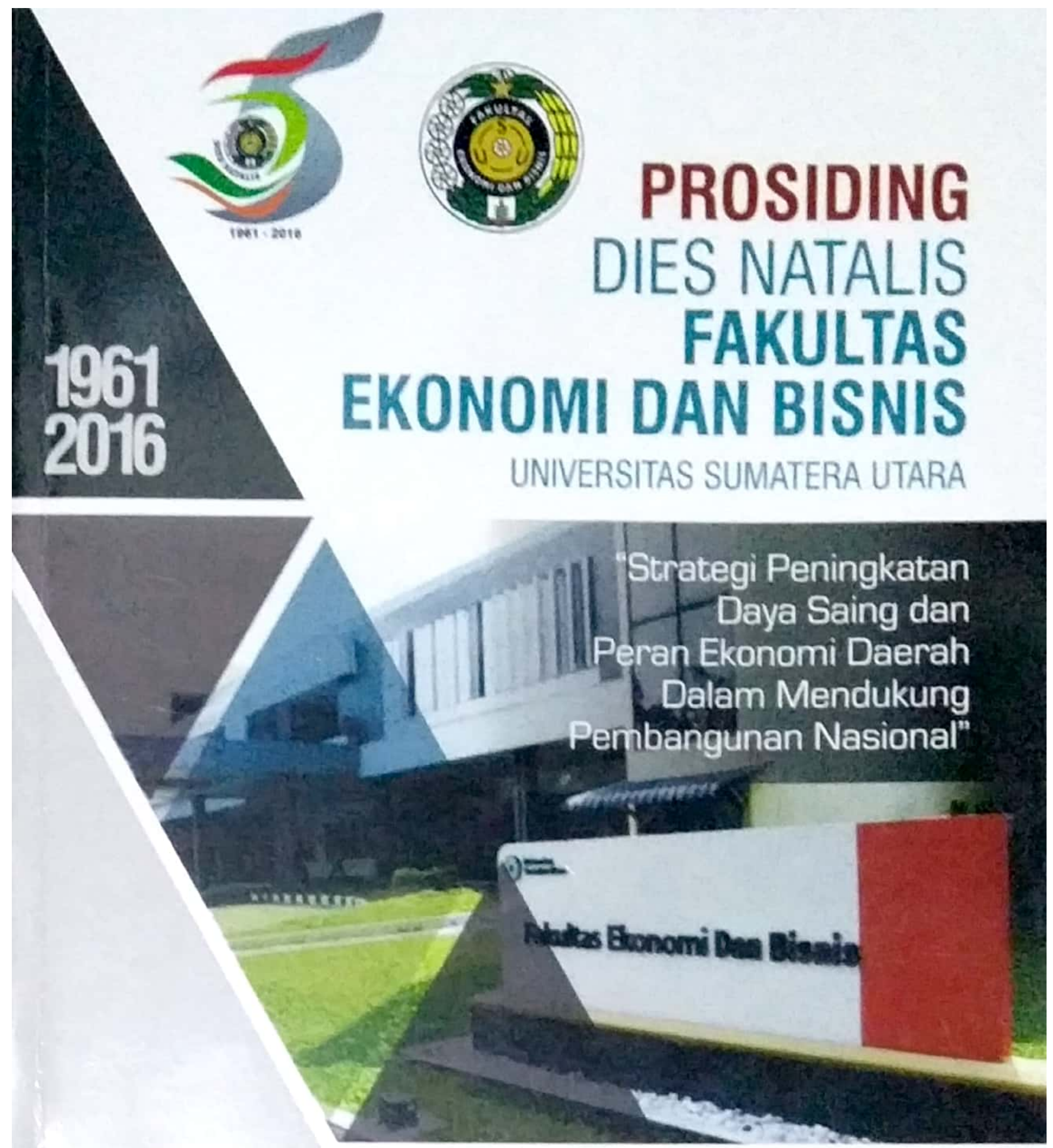

Editor:

Dr. Yeni Absah, S

Dr. Rina Bukit, M

Dr. Sitti Raha Agyes Salim, M.Sc.

Dr. Endang Sulistya Rini, SE, M.Si.

Prot. Dr. Prihatin Lumban Raja, SE, M.Si.
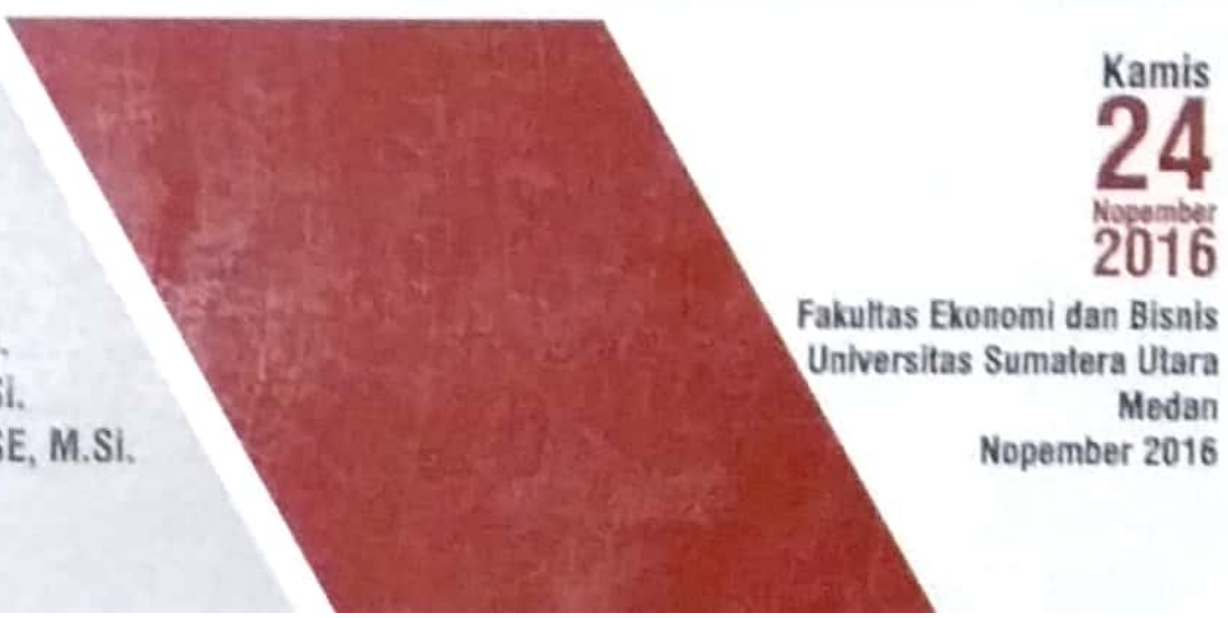

2016

Fakultas Ekonomi dan Bisnis

Universitas Sumatera Utara

Medan

Nopember 2016 


\section{USU Press}

Art Derign. Publishing \& Primting

Gedung F. Pusat Sistem Infarmasi (PSI) Karupus USU

IL. Universitas No. 9

Medan 20155, Indonesia

Telp. 061-8213737; Fax 061-8213737

usupress.usiacic id

O USU Press 2016

Hak cipta dilindungi oleh undang-undang, dilanang memperbanyak memyalin, merekam seluruh bagian buku ini dalam bahasa atau bentuk apapun tanipa izin tertulis dari penerbil

ISBN 9794589179

Perpustakaan Nasional Katalog Dalam Terbitan (KDT)

Prosiding Dies Natalis FEB USU / Editor: Yeni Absah; [et al.] - Medan: USU Press, 2016.

vi, $299 \mathrm{p}$; ilus.; $29 \mathrm{~cm}$

ISBN: 979-458-917-9

1. Ekonomi

I. Judul

Dicetak di Medan, Indonesia 


\section{KATA SAMBUTAN DEKAN}

Assalamualaikum Wr. Wb.

Dies Natalis Fakultas Ekonomi dan Bisnis Univeritas Sumatera Utara ke 55 merupakan ajang silahturahmi bagi alumni Fakultas Ekonomi dan Bisnis Unveritas Sumatera Itara yang saat ini sudah mencapai kurang lebih 21.000 orang. Fakulıas Ekonomi dan Bisnis Univeritas Sumatera Utara sedang dirancang untuk menjadi fakultas dengan standar intemasional, sehingga memerlukan berbagai saran dari pihak termauk alumni, parktisi, dan akadenisi.

Call paper termasuk sarana untuk berbagi ilmu dan hasil penelitian dari kalangan akademisi dan praktisi guna meningkatkan kualitas riset dalan rangki pengembangan ilmu pengetahuan dimasing-masing bidang yang ada dalam setiap departemen di Fakultas Ekonomi dan Bisnis Univeritas Sumatera Utara.

Saya berharap dengan berlangsungnya acara ini dapat memberikan kontribusi yang positif dalam perkembangan konsep dan praktik dunia pendidikan yang terus berkembang. Akhir kata, terima kasih kepada para peserta yang telah hadir dan menyukseskan acara Call Paper dalam rangka peringatan Dies Natalis Fakultas Ekonomi dan Bisnis Univeritas Sumatera
Utara ke 55 .

Wassalam,

Dekan Fakultas Ekonomi dan Bisnis Universitas Sumatera Utara 


\section{DAFTAR ISI}

KATA SAMBUTAN DEKAN

DAFTAR ISI

\section{AKUNTANSI}

ANALISIS PENGARUH PIUTANG TERHADAP LABA PERUSAHAAN (BANK ARTHA

GRAHA INTERNASIONAL, TBK)

Thomas Sumarsan Goh.

PERILAKU INVESTOR DALAM MENGAMBIL KEPUTU

PENDEKATAN KEUANGAN DAN NON Kanta Lestari, Rina Bukit

INTERNAL DALAM MEWUJUDKAN TRANSPARANS! PENTINGNYA PENGENDALIANINTAH PUSAT DAN DAERAH LAPORAN KEUANGAN PEM Tengku Hasan Basri, dan Robiab Afdawiyah, Rina Bukit SANAJEMEN LABA, FRAUD ATAU STRATEG] ACCOUNTING BEHAVIORAL ISSUE: MANaina Rusyda, Rina Bukit SUATU TINJAUAN PERILAKU DALAM CREATIVE ACCO Bukit Yulia Fitri, Musafran Harahap, Z KAJIAN LITERATUR PERILAKU DISEL Hadi Mirsa, Rina Bukit. Intan Arifin, Anisa Fitri, Putri Fadhilla

\section{MANAJEMEN}

PERBANDINGAN SEBELUM PEMBERIAN KREDIT DENGAN SESUDAH ADANYA PEMBERIAN KREDIT MIKRO SUMUT SEJAHTERA II TERHADAP PERKEMBANGAN BISNIS UMKM DI SIMPANG KWALA MEDAN

Bunga Aditi

PENGARUH INOVASI PRODUK DAN SIKAP KONSUMEN TERHADAP KEPUTUSAN AN SAMSUNG GALAXY J7 DI KOTA MEDAN

Wan Suryani

SISTEM SERTIFIKASI KOMPETENSI, PARADIGMA BARU PENYIAPAN TENAGA KERJA BERKUALITAS DI PERUSAHAAN DAN MENGHADAPI PERSAINGAN GLOBAL Tetty Yuliaty

PENGARUH PROMOSI DAN MEREK TERHADAP KEPUTUSAN PEMBELIAN Nel Arianty, SE, MM

MODERASI HARGA ATAS PENGARUH LABEL HALAL TERHADAP KEPUTUSAN PEMBELIAN MAKANANOLAHAN PRODUKSI UKM PADA MAHASISWA FAKULTAS EKONOMU DAN BISNIS UNIVERSITAS SUMATERA UTARA

Yeni Absah 
ANALISIS DISKRIMINAN KUALITAS PELAYANAN PASAR TRADISIONAL PADA PASAR YANG TERTATA DENGAN BAIK DAN BELUM TERTATA DENGAN BAIK Arlina Nurbaity Lubis, Prihatin Lumbanraja.

GENERASI MILLENIAL; NET PROMOTER SCORE DAN NET IMOTTONAL VALUE Syafrizal Helmi Situmorang, Minanda Annisa, Arief Hadian 100

ANALISIS SWOT PADA IMPLEMENTASI MANAJEMEN PRODUKSI UMKM DI SUMATERA UTARA

Lila Bismala

MANAJEMEN STRES DALAM MENEKAN INTENTION TO LEAVE

Elisabet Siahaan

PENGARUH FAKTOR PRIBADI DAN MOTIVASI TERHADAP KEPUTUSAN

PEMBELIAN DI KEUDE KUPIE ULEE KARENG Dr. MANSYUR MEDAN

Muhammad Nursyah Putra Lubis, Beby Karina F Sembiring

PENGARUII MOTIVASI INTRINSIK DAN KOMITMENT ORGANISASI TERHADAP

KINERJA KARYAWAN PADA PT BANK MANIDIR (PERSERO) TBK CLUSTER

MAM BONJOL II

Dahrul Siregar, Ritha F Dalimunthe, Siti Raha Agoes Salim

MODEL VB-SLA GROUP LENDING SEBAGAI ALTERNATIF PEMBIAYAAN UMKM

(Studi Kasus Pada Industri Kerajinan Rotan di Kota Medan)

Hasrul Siregar, May Handri

PENGARUH DISIPLIN DAN LINGKUNGAN KERJA TERIIADAP KEPUASAN KERJA

PEGAWAI PADA UNIVERSITAS MUSLIM NUSANTARA AL WASHLIY AH MEDAN
Hardi Mulyono ............................

PENGARUH PEMBERDAYAAN KARYAWAN DAN GAYA KEPEMIMPINAN TERHADAP

KINERJA SUMBER DAYA MANUSIA PT KEMAS ANUGERAII SWASTIKA MEDAN

Imanuel Tarigan, Desy Permata Sari

PENGARUH CELEBRITY ENDORSEMENT, SIKAP MAIIASISIVA DAN ATRIBUT PRODUK

IERIIADAP MINAT BELI ULANG PADA PRODUK HIIAB DI UNIVERSITAS

PEMBANGUNAN PANCA BUDI MEDAN (STUDI KASUS MAHASISWI UNPAB MEDAN)

Elfitra Desy Surya, Husni Muharram Ritonga

PENGARUH ATRIBUT PRODUK DAN LABEL HALAL SEBAGAI VARIABEL

MODERATING TERHADAP KEPUTUSAN PEMBELIAN PRODUK KOSMETIK WARDAH

DI FAKULTAS EKONOMI UNIVERSITAS MEDAN AREA

Adelina Lubis

PENGARUH SARANA DAN PRASARANA TRANSPORTASI TERHADAP KUALITAS PELAYANAN ANGKUTAN UMUM DI KOTA MEDAN

Alfonsius, Marlon Sihombing, Rujiman, Agus Purwoko

IVAIUASI KINERJA KARYAWAN MELALUI MODEL PELATIHANDAN KECERDASAN

EMOSIONAL PADA PT COCA-COLA BOTTLING INDONESIA NORTHERN SUMATRA

OPIRATION

Febrilian Lestario 
PEOPLE EQUITY: SALAH SATU UPAYA PENGUATAN KINERSA INDUSTRI KREA (SUATU KAJIAN LITERATUR)

Maretta Ginting

EFETHFITAS PENGANGKUTAN TANDAN BUAH SEGAR KELAPA SAWIT (Elaref guineensis Jacq) PADA BEBERAPA KEBUN Na Djs, S.Si., M.Si

GAN PERTUMBUHAN INDUSTRI KREATIF KAIN SONGKE PELUANG DAN TANTANGAN PERTUN STRATEGI BERSAING PORTER

BATUBARA MELALUI PEI

EFISIENSI FAKTOR PRODUKSI TAMBAK IKAN SEMI TRADISIONAL DI KABUPAT DELI SERDANG DENG

DAMPAK SUMBER DAYA MANUSIA DAN BAURAN PEMASARAN TERHADAP KEPUASAN DAN DAYA SAING UMKM INDUSTRI ROTAN DI KOTA MEDAN Jenny Simanjuntak

THE EFFECTS OF SELF-IMAGE AND HABIT ON GREEN PURCHASE INTENTION

AMONG MALAYSIAN CONSUMERS
Azah Afzan Azhari, Baharom Abdul Rahman, Abdul Kadir Othman, Samsudin Wahab ORGANIZATTONAL REWARDS SYSTEM AND EMPLOYEES' SATISFACTION AT A TELECOMMUNICATIONS COMPANY IN MALAYSIA

Baharom Abdul Rahman, Khadijah Zolkeflee, Rudzi Munap, Muhammad Izwan Mohd Badrillah

FACTORS OF APPROVAL OF MICROCREDIT FACILITIES OFFERED BY AMANAH IKHTIAR MALAYSIA (AIM) AT MARANG, TERENGGANU

Adarina Makter, Azemi Che Hamid, Johari Harun

SEKURITISASI KREDIT PEMILIKAN RUMAH SUBSIDI (SUBSIDIES MORTGAGE BAO SEBAGAI SALAH SATU ALTERNATIF PENDANAAN KREDIT

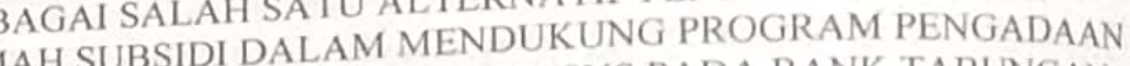
PEMILIKAN RUMAH SUBSIDIDASIA (STUDI KASUS PADA BANK TABUNGAN RUMAH BA

NEGARA)

Ternamentha Sitepu

PENGARUH TARIF DAN JENIS PRODUK ASURANSI TERHADAP PENCAPAIAN TARGET PENJUALAN PADA ASURANSI JIWA BERSAMA BUMIPUTERA 1912 CABANGTANJUNG BALAI

Halimatussaddiah Marpaung

PENGARUH KUALITAS PRODUK, HARGA DAN CITRA MEREK PASTA GIGI PEPSODENT TERHADAP LOYALITAS KONSUMEN DI KOTA TANJUNGBALAI (STUDY KASUS DI KELURAHAN PERJUANGAN KECAMATAN TELUK NIBUNG) Tengku Syarifah

ANALISIS FAKTOR - FAKTOR YANG MEMPENGARUHI PRODUKSI TAHU DI KOTA KISARAN

Muhammad Ansori 


\title{
PERBANDINGAN SEBELUM PEMBERIAN KREDIT DENGAN SESUDAH ADANYA PEMBERIAN KREDIT MIKRO SUMUT SEJAHTERA II TERHADAP PERKEMBANGAN BISNIS UMKM DI SIMPANG KWALA MEDAN
}

\author{
Bunga Aditi \\ Program Studi Manajemen, Sekolah Tinggi Ilmu Ekonomi Harapan Medan \\ email: bunga.aditi09@yahoo.com
}

\begin{abstract}
Implementation of Microcredit Sumatra Prosperous II guided by the manual instructions in awarding credit on Microcredit Sumatra Prosperous II. The purpose of this study was to determine and analyze to determine and analyze the comparison before giving credit after the administration of Microcredit Sumatra II on the development of the business Prosperous Small Medium Micro Enterprises in Kwala Simpang Medan.Pengumpulan data in this research is conducted through a survey approach with quantitative descriptive research by spreading the questionnaire. Data analysis method used is to use surgical test using SPSS software. The results showed the simultaneous realization of loans, ease of procedures, speed of execution and credit requirements simultaneously positive and significant impact on the Improvement of Small Micro. Partially credit realization, ease of procedures, speed of execution and significant effect on the credit terms Increased PT Bank Micro, Small and Kwala Simpang Branch Medan North Sumatra. Results of research for the variable Before Lending $\left(X_{1}\right)$ is known Ho is rejected while $H_{1}$ accepted, meaning the Microcredit Sumatra after the administration of the development of business Prosperous II Small Medium Micro Enterprises develops. This means that with the provision of Microcredit Sumatra Prosperous II the development of business increased Micro Small Medium and increase the number of customers who were shopping at Kwala Simpang Medan.
\end{abstract}

Keywords: Before Lending, After existence of granting Micro Sumatra Prosperous II. 


\section{PENDAHULUAN}

Usaha Menengah Kecil Mikro Kota

Medan dalam beberapa tahun belakangan terus "menggeliat" dengan semakin banyaknya masyarakat yang menekuni usaha rumahan tersebut sebagai mata pencaharian utama mau pun sampingan.

Kepala Dinas Koperasi dan Usaha Menengah Kecil Mikro (UMKM) Kota Medan mengatakan, dewasa ini perkembangan UMKM di ibukota provinsi Sumatera Utara khusus kota Medan itu terus menunjukkan pertumbuhan yang cukup signifikan.

Tingginya tingkat pertumbuhan UMKM tersebut dinilai tentu juga tidak terlepas dari semakin gencarnya pemerintah mendorong masyarakat untuk menjadi enterpreuner yang juga sekaligus mampu membuka lapangan pekerjaan baru. Sehingga tingginya angka pengangguran yang dewasa ini jumlahnya semakin mengkhawatirkan terutama pada kalangan usia produktif dapat semakin ditekan.

Tahun 2009 ada sekitar 22 ribu pelaku UMKM di Kota Medan dan jumlah itu terus meningkat hingga tahun 2015 jumlahnya sekitar mencapai 300 ribu. Tingginya pertumbuhan UMKM tersebut tentunya sangat menggembirakan karena juga sekaligus dapat menekan angka pengangguran," katanya. Agar UMKM tersebut dapat terus bertahan terutama untuk menghadapi Masyarakat Ekonomi ASEAN (MEA), pihaknya terus berupaya melakukan pendampingan terutama dalam hal pemasaran hasil produksi yang dihasilkan dan promosi sehingga masyarakat luas lebih mengenal hasil produksi yang ada.

Pelatihan-pelatihan serta pameran juga rutin digelar, bukan hanya di Kota Medan namun ke berbagai daerah di Indonesia, dengan harapan SDM dan kualitas produksi yang dihasilkan semakin tersebar dan semakin digemari masyarakat seiring dengan imbauan pemerintah untuk mencintai produk-produk dalam negeri. Yang tidak kalah pentingnya tentunya pelaku UMKM juga harus kreatif dalam menghasilkan produk yang inovatif dan berkualitas sehingga mampu bersaing dengan produk luar.

Industri perbankan menyadari bahwa debitur saat ini tidak hanya mempertimbangkan faktor bunga atau kecanggihan dan kelengkapan fitur dari suatu produk perbankan, tetapi nilai (value) akan didapatkan dari apa yang ditawarkan oleh pihak bank, sehingga pada akhirnya akan bersedia untuk menjadi debitur yang loyal (Bielen et al. 2007). Secara teoretis merujuk pada hasil penelitian terdahulu bahwa kepuasan debitur dan loyalitas debitur dipercaya mampu memberikan dampak yang positif dan pengaruh yang signifikan bagi 
kelangsungan bank baik dalam jangka pendek maupun untuk jangka panjang (Liu et al. 2007).

KUR adalah program yang dicanangkan oleh pemerintah namun sumber dananya berasal sepenuhnya dari dana bank. Pemerintah memberikan penjaminan terhadap resiko KUR sebesar $70 \%$ sementara sisanya sebesar $30 \%$ ditanggung oleh bank pelaksana. Penjaminan KUR diberikan untuk meningkatkan akses UMKM pada sumber pembiayaan. Dengan adanya KUR, para pelaku UMKM dapat meminjam modal hanya dengan jaminan kelayakan usaha dan diharapkan kepada pelaku UMKM tersebut dapat mengembangkan usahanya. Tahap awal program, KUR ini disediakan hanya terbatas oleh bank-bank yang ditunjuk oleh pemerintah saja, yaitu : Bank Rakyat Indonesia (BRI), Bank Negara Indonesia (BNI), Bank Mandiri, Bank Syariah Mandiri, Bank Tabungan Negara dan Bank Bukopin.

Penyaluran pola penjaminan difokuskan pada lima sektor usaha, yaitu pertanian, perikanan dan kelautan, koperasi, kehutanan, serta perindustrian dan perdagangan. KUR ini ditujukan untuk membantu ekonomi usaha rakyat kecil dengan cara memberi pinjaman untuk usaha yang didirikannya. Atas diajukannya permohonan peminjaman kredit tersebut, tentu saja harus mengikuti berbagai prosedur yang ditetapkan oleh bank yang bersangkutan. Selain itu, pemohon harus mengetahui hak dan kewajiban yang akan timbul dari masing-masing pihak yaitu debitur dan kreditur dengan adanya perjanjian KUR, mengingat segala sesuatu dapat saja timbul menjadi suatu permasalahan apabila tidak ada pengetahuan yang cukup tentang KUR.

Salah satu manfaat yang dirasakan debitur terhadap keberhasilan untuk bertahan dalam masa krisis dan menjadikan Usaha Mikro, Kecil dan Menengah (UMK) mampu berkembang dengan baik karena adanya program bantuan yang diberikan Bank dalam meningkatkan UMK. Posisi UMK mempunyai peranan strategis, indikasi yang menunjukkan dilihat dari kontribusi terhadap PDB, Ekspor non-migas, penyerapan tenaga kerja dan peningkatan kualitas sumber daya manusia yang cukup berarti (Irfan, 200:48).

Peranan perbankan sudah sesuai dengan tujuan dalam meningkatkan UMK, namun karena lambannya perkembangan usaha UMK dalam mengembalikan modal awal sehingga usaha tersebut tidak berjalan dengan baik yang mengakibatkan banyak kredit macet debitur. Hal ini berdampak kepada sebagian UMK yang akan melakukan kredit karena bank merasa 
sektor ini belum layak mendapatkan akses perbankan. Peranan pemerintah dalam mengatasi permasalahan ini tidak menunjukkan adanya perhatian yang dirasakan pelaku UMK.

Hasil kajian terhadap UMK mengin- dikasikan bahwa salah satu faktor dominan dalam pengembangan UMK adalah faktor permodalan. Untuk itu diperlukan peranan dari sektor perbankan dalam penyediaan permodalan bagi UMK karena kredit bank masih merupakan alternatif sumber permodalan bagi UMK. Namun permasalahan UMK dalam mengakses kredit perbankan masih terkendala antara lain, umumnya UMK belum mempunyai pembukuan yang jelas sehingga menyulitkan perbankan untuk mengetahui informasi mengenai usaha tersebut secara lengkap, masih banyaknya UMK belum terdaftar sebagai badan usaha resmi, kurangnya kemampuan sumberdaya manusia yang mengelola UMK dan faktor akses pemasaran produk yang dihasilkan.

Permasalahan lain yang dikeluhkan UMK dalam menghadapi perbankan sebagaimana terekam dalam berbagai acara temu wicara antara UMK, perbankan dan pemerintah antara lain: persyaratan agunan dalam permohonan kredit, langkanya sumber dana murah perbankan, persyarakatan kredit yang sulit dipenuhi, tingginya suku bunga kredit, pendampingan/konsultasi untuk UMK dan terbatasnya informasi pengembangan usaha.

Banyak keluhan UMK terkait dengan sulitnya mendapatkan permodalan dari perbankan yang berdampak pada Kredit Mikro Sumut Sejahtera II. Secara umum permasalahan yang terjadi adalah adanya perbedaan persepsi antara UMK dengan bank, khususnya mengenai kelayakan kredit. UMK memiliki usaha yang prospektif dan menguntungkan (feasible) namun demikian belum layak dari kacamata bank (bankable) karena minimnya agunan, atau agunan yang dimiliki kurang mencukupi dalam mengcover risiko kredit. Oleh karena itu untuk mencari jalan keluarnya, perlu melihat permasalahan tersebut dari dua sisi secara berimbang yakni dari sisi perbankan maupun dari sisi UMK itu sendiri.

Berdasarkan latar belakang yang telah diuraikan sebelumnya, maka peneliti tertarik untuk melakukan penelitian yang berjudul“ $\quad$ Perbandingan $\quad$ Sebelum Pemberian Kredit Dengan Sesudah Adanya Kredit Mikro Sumut Sejahtera II terhadap Perkembangan Bisnis Umkm di Simpang Kwala Medan”.

\subsection{Tujuan dan Manfaat Penelitian}

\section{Tujuan Penelitian}

Untuk mengetahui dan menganalisis Perbandingan sebelum pemberian kredit 
dengan sesudah pemberian Kredit Mikro

Sumut Sejahtera II terhadap perkembangan bisnis UMKM di Simpang Kwala Medan.

\section{Manfaat Penelitian}

1. Bagi PT Bank Sumut Cabang Simpang Kwala Medan, sebagai masukan dalam melihat perbandingan sebelum pemberian kredit dengan sesudah pemberian Kredit Mikro Sumut Sejahtera II terhadap perkembangan bisnis UMKM di Simpang Kwala Medan

2. Bagi peneliti, agar dapat mengaplikasikan teori selama masa studi dan menerapkan ilmu pengetahuan yang diperoleh di perguruan tinggi dan juga untuk memperluas wawasan pemikiran dan mempertajam kemampuan pengamatan.

3. Bagi peneliti selanjutnya sebagai referensi dalam melakukan penelitian khususnya mengenai sebelum pemberian kredit dengan sesudah adanya pemberian Kredit Mikro Sumut Sejahtera II terhadap perkembangan bisnis UMKM di Simpang Kwala Medan

\section{LANDASAN TEORI}

\subsection{Kredit Mikro Sumut Sejahtera II}

Pengertian Keputusan Debitur dalam Mengambil Kredit yaitu sebuah proses keputusan mengambil kredit pada suatu bank (Kotler, 2009:139), menurut (Griffin, 2006:81) Keputusan Debitur dalam Mengambil Kredit adalah suatu tindakan memilih satu alternatif dari serangkaian alternatif yang ada. Menurut Schiffman (2004:71) Keputusan Debitur dalam Mengambil Kredit adalah pemilihan dari dua atau lebih alternatif pilihan keputusan pengambilan kredit, artinya bahwa seseorang dapat membuat keputusan, haruslah tersedia alternatif lainnya.

Pengertian Prosedur Kredit adalah tahapan yang dilakukan bank dalam rangka melayani permintaan debitur dalam pengambilan kredit. Sebelum debitur memperoleh kredit terlebih dahulu harus melalui tahapan-tahapan penilaian mulai dari pengajuan proposal kredit dan dokumen-dokumen yang diperlukan, pemeriksaan keaslian dokumen, analisis kredit sampai dengan kredit dikeluarkan oleh pihak bank.

Menurut Hasibuan (2006:186) Prosedur Kredit adalah suatu tahapantahapan yang harus dipenuhi oleh debitur dalam penyaluran kredit.

Prosedur Kredit dapat diartikan sebagai upaya bank dalam mengurangi resiko 
dalam pemberian kredit, yang dimulai dengan tahapan penyusunan perencanaan pengkreditan, dilanjutkan dengan proses pemberian keputusan kredit (prakarsa, analisis dan evaluasi, negosiasi, rekomendasi dan pemberian keputusan kredit), penyusunan pemberian kredit, dokumentasi dan administrasi kredit, persetujuan pencairan kredit serta pengawasan dan pembinaan kredit.

\subsection{Usaha Mikro Kecil (UMK)}

Keputusan UU No. 20 Tahun 2010. Definisi UKM yang disampaikan berbedabeda antara satu dengan yang lainnya. Menurut Kementrian Menteri Negara Koperasi dan Usaha Kecil Menengah (Menegkop dan UKM), bahwa yang dimaksud dengan Usaha Kecil (UK), termasuk Usaha Mikro (UMI), adalah entitas usaha kekayaan bersih paling banyak Rp 200.000.000, tidak termasuk tanah dan bangunan tempat usaha, dan memiliki penjualan tahunan paling banyak Rp 1.000.000.000. Sementara itu, Usaha Menengah (UM) merupakan entitas usaha milik warga negara Indonesia yang memiliki kekayaan bersih lebih besar dari Rp 200.000.000 sampai dengan $\mathrm{Rp}$ 10.000.000.000 tidak termasuk tanah dan bangunan.

Badan Pusat Statistik (BPS) memberikan definisi UKM berdasarkan kuantitas tenaga kerja. Usaha kecil merupakan entitas usaha yang memiliki jumlah tenaga kerja 5 sampai dengan 19 orang, sedangkan usaha menengah merupakan entitias usaha yang memiliki tenaga kerja 20 sampai dengan 99 orang. Berdasarkan Keputuasan Menteri Keuangan Nomor 316/KMK.016/1994 tanggal 27 Juni 1994, usaha kecil didefinisikan sebagai perorangan atau badan usaha yang telah melakukan kegiatan/usaha yang mempunyai penjualan/omset per tahun setinggitingginya $\mathrm{Rp} 600.000 .000$ atau aset/aktiva setinggi-tingginya Rp 600.000.000 (di luar tanah dan bangunan yang ditempati) terdiri dari : (1) badang usaha (Fa, CV, PT, dan Koperasi) dan (2) perorangan (pengrajin/industri rumah tangga, petani, peternak, nelayan, perambah hutan, penambang, pedagang barang dan jasa).

Menurut Hidayat (2012:74) Usaha Mikro Kecil Menengah adalah kegiatan usaha yang mampu memperluas lapangan kerja, memberikan pelayanan ekonomis secara luas kepada masyarakat, berperan dalam proses pemerataan dan peningkatan pendapatan masyarakat, mendorong pertumbuhan ekonomi dan berperan dalam mewujudkan stabilitas nasional.

Menurut Hidayat (2012) Usaha Mikro Kecil Menengah adalah Kegiatan usaha yang mampu memperluas lapangan 
kerja, memberikan pelayanan ekonomis secara luas kepada masyarakat, berperan dalam proses pemerataan dan peningkatan pendapatan masyarakat, mendorong pertumbuhan ekonomi dan berperan dalam mewujudkan stabilitas nasional.

Manfaat bagi UKM menjalani kemitraan usaha dengan usaha lain,

1. Meningkatkan Produktivitas.

2. Meningkatkan efisiensi.

3. Mengurangi resiko kerugian.

4. Meningkatkan stabilitas ekonomi nasional.

UKM di negara berkembang, seperti di Indonesia, sering dikaitkan dengan masalah-masalah ekonomi dan sosial dalam negeri seperti tingginya tingkat kemiskinan, besarnya jumlah pengangguran, ketimpangan distribusi pendapatan, proses pembangunan yang tidak merata antara daerah perkotaan dan perdesaan, serta masalah urbanisasi.

\subsection{Kerangka Pemikiran}

Keputusan yang tepat sangat penting dalam mengambil kredit pada bank. Keputusan ini bermaksud agar tidak adanya hambatan besar maupun kecil pada saat mengambil kredit dikemudian hari, sehingga perlu diambil suatu keputusan yang sangat tepat. Pada saat melakukan kredit di bank, bank dapat meningkatkan sarana kredit dan meningkatkan tempat lokasi bank yang baik dan nyaman untuk debitur melakukan transaksi kredit. Ketika melakukan kredit diperlukan ketelitian pada saat memutuskan kredit agar nantinya tidak kecewa mengambil kredit dan tidak telat pada saat mengembalikannya, pada saat jatuh tempo yang ditentukan oleh bank.

Kredit merupakan salah satu kegiatan pokok pendapatan daerah, selain tabungan dan deposito, dengan ini dalam melakukan penilaian dari beberapa calon debitur kredit harus berhati-hati dalam mengambil keputusan yang harus dapat dipertanggung jawabkan agar salah satu pihak nantinya tidak ada yang merasa dirugikan.

\subsection{Hipotesis}

Adanya perbandingan sebelum pemberian kredit dengan sesudah pemberian Kredit Mikro Sumut Sejahtera II terhadap perkembangan bisnis UMKM di Simpang Kwala Medan.

\section{METODE PENELITIAN}

\subsection{Populasi dan Sampel}

Populasi dalam penelitian ini adalah UMKM yang menerima Kredit Mikro Sumut Sejahtera II berjumlah 30 orang di PT Bank Sumut Cabang Simpang Kwala Medan. Untuk menentukan jumlah sampel dengan ukuran populasi diketahui maka digunakan sample jenuh. Jadi jumlah 
sampel yang digunakan dalam penelitian dengan menggunakan metode sensus adalah seluruh populasi dijadikan sampel.

\subsection{Defenisi Operasional}

Berdasarkan perumusan masalah, kerangka konseptual dan hipotesis yang diajukan maka variable-variabel dalam penelitian ini yaitu Variabel Sebelum Pemberian Kredit $\left(\mathrm{X}_{1}\right)$ dan Setelah Adanya pemberian Mikro Sumut Sejahtera II $\left(\mathrm{X}_{2}\right)$

\subsection{Metode Analisis Data}

Dalam upaya pembuktian atas hipotesis yang dibuat maka harus dilakukan pengujian atas hipotesis itu dengan menggunkan metode penelitian yang sesuai seperti: Mann-Whitney U-Test yang digunakan untuk menguji signifikansi hipotesis komparatif dua sampai independen bila datanya berbentuk ordinal. Test ini merupakan test yang terbaik untuk menguji hipotesis komperatif dua sampel independen bila datanya berbentuk ordinal.

Bila dalam suatu pengamatan data berbentuk interval, maka perlu dirubah dulu kedalam data ordinal. Bila data masih berbentuk interval, sebenarnya dapat menggunakan t-test untuk pengujiannya, tetapi bila asumsi t-test tidak dipenuhi (misalnya data harus normal), maka test ini tidak dapat digunakan.

Terdapat dua rumus yang digunakan untuk pengujian, yaitu rumus 9,26 dan
9,29 kedua rumus tersebut digunakan dalam perhitungan, karena akan digunakan untuk mengetahui harga $U$ mana yang lebih kecil. Harga U yang lebih kecil tersebut yang digunakan untuk pengujian dana membandingkan dengan $\mathrm{U}$ tabel.

Statistic deskriptif adalah statistik yang digunakan untuk mengalisis data dengan cara mendeskripsikan atau menggambarkan data yang telah terkumpul sebagaimana adanya tanpa bermaksud membuat kesimpulan yang berlaku untuk umum dan generalisasi

\section{ANALISIS DAN PEMBAHASAN}

\subsection{Analisis Deskriptif Responden}

Analisis deskriptif dalam penelitian ini merupakan uraian atau penjelasan dari hasil pengumpulan data primer berupa kuesioner yang telah diisi oleh responden penelitian. Responden penelitian ini berjumlah 30 responden.

Karakteristik

Responden berdasarkan Jenis Kelamin dapat dilihat pada Tabel 1:

\section{Tabel 1}

\section{Karakteristik berdasarkan Jenis}

Kelamin

\begin{tabular}{|l|r|r|}
\hline Jenis_Kelamin & Count & \multicolumn{1}{|c|}{ Column N \% } \\
\hline Laki-laki & 17 & $56.7 \%$ \\
Perempuan & 13 & $43.3 \%$ \\
\hline
\end{tabular}

Sumber: Hasil Penelitian, 2016 (data diolah) 
Berdasarkan data pada Tabel 1 dapat dilihat bahwa dari 30 responden yang paling banyak berjenis kelamin lakilaki sebanyak 17 orang atau 56,7\% dan berjenis kelamin perempuan sebanyak 13 orang atau 43,3\%. Dari data yang diperoleh tersebut maka dapat kita lihat bahwa jenis kelamin laki-laki yang paling banyak dalam anggota UMKM.

Karakteristik

Responden berdasarkan Pendidikan dapat dilihat pada Tabel 2:

\section{Tabel 2}

\section{Karakteristik berdasarkan Pendidikan}

\begin{tabular}{|c|r|r|}
\hline Pendidikan & Count & Column N \% \\
\hline D3 & 8 & $26.7 \%$ \\
S1 & 7 & $23.3 \%$ \\
SMA & 15 & $50.0 \%$ \\
\hline
\end{tabular}

Sumber: Hasil Penelitian, 2016 (data diolah)

Berdasarkan data pada Tabel 2 dapat dilihat bahwa dari 30 responden yang paling banyak memiliki pendidikan SMA sebanyak 15 orang atau $50 \%$ dan memiliki pendidikan S1 yang lebih sedikit sebanyak 7 orang atau 23,3\%. Dari data yang diperoleh tersebut maka dapat kita lihat bahwa pendidikan SMA yang paling banyak sebagai.
Berdasarkan Penghasilan dari

UMKM dapat dilihat pada Tabel 3:

Tabel 3 Berdasarkan Penghasilan dari UMKM

\begin{tabular}{|l|c|c|c|c|c|}
\hline & N & Min & Max & Mean & $\begin{array}{l}\text { Std. } \\
\text { Dev }\end{array}$ \\
\hline $\begin{array}{l}\text { Pendapatan } \\
\text { UMKM }\end{array}$ & 30 & $1,000,000$ & $7,000,000$ & $3,096,666$ & $1,479,86$ \\
$\begin{array}{l}\text { Pendapatan } \\
\text { Sampingan }\end{array}$ & 30 & 0 & 900,000 & 240,300 & 319,477 \\
$\begin{array}{l}\text { Diluar } \\
\text { UMKM }\end{array}$ & 30 & & & & \\
Valid N \\
(listwise)
\end{tabular}

Sumber: Hasil Penelitian, 2016 (data diolah)

Berdasarkan data pada Tabel 3 dapat dilihat bahwa berdasarkan penghasilan dari UMKM adalah pendapatan terendah sebesar Rp.1.000.000 sedangkan pendapatan tertinggi dari UMKM adalah sebesar Rp.7.000.000, sedangkan rata-rata pendapatan dari UMKM adalah sebesar Rp. 3.096.666 dan standar deviasi adalah sebesar Rp.1.479.860. Hal ini menunjukkan bahwa pendapatan dari UMKM berdistribusi normal.

$$
\text { Penghasilan keluarga untuk }
$$
pendapatan diluar dari UMKM adalah pendapatan terendah sebesar 0 atau tidak ada sedangkan pendapatan tertinggi adalah sebesar Rp.900.000, sedangkan rata-rata pendapatan diluar dari UMKM adalah sebesar Rp. 240.300 dan standar deviasi adalah sebesar Rp.319.477. Hal ini menunjukkan bahwa pendapatan diluar UMKM berdistribusi normal. 


\subsection{Pengujian Hipotesis}

Dalam upaya pembuktian atas hipotesis yang dibuat maka harus dilakukan pengujian atas hipotesis itu dengan menggunkan metode penelitian yang sesuai. Pengujian hipotesis untuk melihat perbandingan sebelum pemberian kredit dengan sesudah pemberian Kredit Mikro Sumut Sejahtera II terhadap perkembangan bisnis UMKM di Simpang Kwala Medan.

\section{One-Sample Statistics}

Hasil uji dari pengujian hipotesis dengan uji beda dapat dilihat pada Tabel 4 One-Sample Statistics

\section{Tabel 4}

\section{One-Sample Statistics}

\begin{tabular}{|c|c|c|c|c|}
\hline & $\mathrm{N}$ & Mean & $\begin{array}{c}\text { Std. } \\
\text { Deviation }\end{array}$ & $\begin{array}{c}\text { Std. Error } \\
\text { Mean }\end{array}$ \\
\hline $\mathrm{X} 1$ & 30 & 1.5667 & .50401 & .09202 \\
\hline $\mathrm{X} 2$ & 30 & 1.7333 & .44978 & .08212 \\
\hline
\end{tabular}

Sumber: Hasil Penelitian, 2016 (data diolah

Pada Tabel 3 Hasil dari OneSample Statistics menunjukan nilai statistik variabel Sebelum Pemberian Kredit $\left(\mathrm{X}_{1}\right)$ sebagai berikut: jumlah sampel $(n)=30$, rata-rata Sebelum Pemberian Kredit $\left(\mathrm{X}_{1}\right)$ sebesar 1,56, standar deviasi 0,50 dan std eror Mean $=0,09$.
Hasil One-Sample Statistics menunjukkan nilai statistik variabel dan Setelah Adanya pemberian Mikro Sumut Sejahtera II sebagai berikut: jumlah sampel (n) $=30$, rata-rata Setelah Adanya pemberian Mikro Sumut Sejahtera II $\left(\mathrm{X}_{2}\right)$ sebesar 1,73, standar deviasi 0,44 dan std eror Mean $=0,08$.

\section{One-Sample Test}

Tabel 5

One-Sample Test

\begin{tabular}{|l|r|r|r|r|r|r|}
\hline \multirow{7}{*}{} & \multicolumn{6}{|c|}{ Test Value $=0$} \\
\cline { 2 - 7 } & \multicolumn{6}{|c|}{$95 \%$ Confidence Interval of the Difference } \\
\cline { 2 - 7 } & $\mathrm{T}$ & $\mathrm{df}$ & $\begin{array}{r}\text { Sig. (2- } \\
\text { tailed) }\end{array}$ & $\begin{array}{c}\text { Mean } \\
\text { Difference }\end{array}$ & Lower & Upper \\
\hline X1 & 17.026 & 29 & .000 & 1.56667 & 1.3785 & 1.7549 \\
X2 & 21.108 & 29 & .000 & 1.73333 & 1.5654 & 1.9013 \\
\hline
\end{tabular}

Sumber: Hasil Penelitian, 2016 (data diolah)

Pada Tabel 5 Hasil dari OneSample Test untuk kriteria pengujian hipotesisnya. Selain dengan membandingkan nilai $\mathrm{t}$ hitung dengan nilai pada tabel $t$, di SPSS juga bisa menggunakan nilai Sig, jika Sig > 0,05 maka Ho diterima dan jika Sig $<0,05$ maka Ho ditolak.

Pada hasil output untuk variabel sebelum pemberian kredit $\left(\mathrm{X}_{1}\right)$ diketahui Sig $(2$-tailled $)=0,000<0,05$ maka $\mathrm{Ho}$ ditolak sedangkan $\mathrm{H}_{1}$ diterima, artinya sesudah pemberian Kredit Mikro Sumut Sejahtera II maka perkembangan bisnis 
UMKM semakin berkembang di Simpang Kwala Medan $\left(\mathrm{X}_{1}\right)$ dibandingkan dengan sebelum pemberian kredit. Artinya dengan adanya sesudah pemberian Kredit Mikro Sumut Sejahtera II maka perkembangan bisnis UMKM semakin meningkat di Simpang Kwala Medan. Manfaat lain sesudah pemberian Kredit Mikro Sumut Sejahtera II maka perkembangan bisnis UMKM semakin berkembang di Simpang Kwala Medan yaitu tentang kondisi lingkungan sekitarnya semakin ramai dikunjungi pelanggan,

Pada hasil output untuk variabel sesudah pemberian Kredit Mikro Sumut Sejahtera II $\left(\mathrm{X}_{2}\right)$ diketahui Sig (2-tailled) $=0,000<0,05$ maka Ho ditolak sedangkan $\mathrm{H}_{1}$ diterima, artinya sesudah pemberian Kredit Mikro Sumut Sejahtera II maka perkembangan bisnis UMKM semakin berkembang di Simpang Kwala Medan $\left(\mathrm{X}_{2}\right)$ dibandingkan dengan sebelum pemberian kredit. Artinya dengan adanya Bantuan perbankan maka perkembangan bisnis UMKM semakin berkembang di Simpang Kwala Medan

\subsection{Pembahasan}

Perekonomian di Indonesia secara nasional telah menunjukkan bahwa kegiatan Usaha Mikro, Kecil dan Menengah (UMKM) merupakan salah satu bidang usaha yang konsisten dan berkembang. Dengan adanya krisis ekonomi yang melanda Indonesia sejak tahun 1997, Koperasi bahkan menjadi penyelamat bagi perekonomian negara karena potensi Usaha Mikro, Kecil dan Menengah (UMKM) memberikan sumbangan terbesar dan signifikan pada Produk Domesik Bruto (PDB) dalam penyerapan tenaga kerja.

Usaha Mikro Kecil dan Menengah (UMKM) mempunyai peran yang strategis dalam pembangunan ekonomi nasional. Pada saat krisis ekonomi yang terjadi tahun 1997, dimana banyak usaha berskala besar yang mengalami stagnasi bahkan berhenti aktifitasnya, sektor UMKM terbukti lebih tangguh dalam menghadapi krisis tersebut. Peranan UMKM, terutama sejak krisis ekonomi dapat dipandang sebagai katup pengaman dalam proses pemulihan ekonomi nasional, baik dalam mendorong laju pertumbuhan ekonomi nasional maupun penyerapan tenaga kerja.

$$
\text { Suryadharma Ali }
$$

menyatakan bahwa UMKM merupakan benteng pertahanan ekonomi nasional sehingga bila sektor tersebut diabaikan sama artinya tidak menjaga benteng pertahanan Indonesia. Sebagai upaya untuk meningkatkan kemampuan dan peranan serta kelembagaan UMKM dalam perekonomian nasional, maka pemberdayaan tersebut perlu dilaksanakan 
oleh Pemerintah, Pemerintah Daerah, Dunia Usaha, dan Masyarakat secara menyeluruh, sinergis dan berkesinambungan. Untuk mewujudkan hal tersebut maka Pemerintah mengesahkan UU No 20 Tahun 2008 tentang Usaha Mikro Kecil dan Menengah. Undang-undang ini disusun dengan maksud untuk memberdayakan usaha mikro kecil dan menengah. Walaupun usaha mikro kecil menengah telah menunjukkan peranannya dalam perekonomian nasional namun masih menghadapi berbagai hambatan dan kendala.

Pada dasarnya hambatan dan kendala yang dihadapi para pelaku UMKM dalam meningkatkan kemampuan usaha sangat kompleks dan meliputi berbagai aspek yang mana satu dengan yang lainnya saling berkaitan antara lain: kurangnya permodalan baik jumlah maupun sumbernya, kurangnya kemampuan manajerial dan keterampilan beroperasi serta tidak adanya bentuk formil dari perusahaan, lemahnya organisasi dan terbatasnya pemasaran. Disamping itu terdapat juga persaingan yang kurang sehat dan desakan ekonomi sehingga mengakibatkan ruang lingkup usaha menjadi terbatas. Beragamnya hambatan dan kendala yang dihadapi UMKM, tampaknya masalah permodalan masih merupakan salah satu faktor kritis bagi UMKM, baik untuk pemenuhan kebutuhan modal kerja maupun modal investasi dalam pengembangan usaha

Salah satu ciri umum yang melekat pada Usaha Mikro Kecil dan Menengah (UMKM) di Indonesia adalah permodalan yang masih lemah. Padahal modal merupakan faktor yang sangat penting dalam mendukung peningkatan produksi dan kinerja Usaha Mikro, Kecil dan Menengah (UMKM) itu sendiri, terlebih pada pengusaha mikro maupun pedagang golongan ekonomi lemah (usaha kecil). Pada kalangan ekonomi lemah ini biasanya terdapat masalah yaitu kekurangan modal, sehingga seringkali mengalami hambatan dan kesulitan dalam mengembangkan usahanya.

Pengusaha atau pedagang kecil kerap kali terjebak dengan kebutuhan permodalan dan untuk mengambil cara cepat pedagang maupun pengusaha mikro akan meminta bantuan permodalan dana atau kredit usaha kepada rentenir atau praktek lintah darat tersebut. Banyak dari pengusaha atau pedagang kecil ini tidak terlalu memperhatikan persyaratanpersyaratan yang harus dipenuhi kepada si renternir sebelum meminjam sejumlah uang atau modal karena kebutuhan yang sangat mendesak. 
Pada akhirnya pengusaha mikro dan pedagang kecil ini terjerat hutang yang makin lama makin bertambah banyak serta bunga pinjamannya menjadi tinggi karena belum dapat atau tidak dapat melunasi apa saja yang menjadi kewajiban dan tanggung jawab atas perjanjian terhadap renternir tersebut sesuai tempo waktu yang telah ditetapkan. Akhirnya akan berdampak negatif pada hasil bidang usahanya yang lama kelamaan akan menjadi kurang produktif dan menurun bahkan akan dapat mematikan usahanya sendiri atau gulung tikar.

Perkembangan UMKM yang meningkat dari segi kuantitas tersebut belum diimbangi oleh meratanya peningkatan kualitas UMKM.

Permasalahan klasik yang dihadapi yaitu rendahnya produktivitas. Keadaan ini disebabkan oleh masalah internal yang dihadapi UMKM yaitu: rendahnya kualitas SDM UMKM dalam manajemen, organisasi, penguasaan teknologi, dan pemasaran, lemahnya kewirausahaan dari para pelaku UMKM, dan terbatasnya akses UMKM terhadap permodalan, informasi, teknologi dan pasar, serta faktor produksi lainnya.

Sedangkan masalah eksternal yang dihadapi oleh UMKM diantaranya adalah besarnya biaya transaksi akibat iklim usaha yang kurang mendukung dan kelangkaan bahan baku. Juga yang menyangkut perolehan legalitas formal yang hingga saat ini masih merupakan persoalan mendasar bagi UMKM di Indonesia, menyusul tingginya biaya yang harus dikeluarkan dalam pengurusan perizinan. Sementara itu, kurangnya pemahaman tentang koperasi sebagai badan usaha yang memiliki struktur kelembagaan (struktur organisasi, struktur kekuasaan, dan struktur insentif) yang unik/khas dibandingkan badan usaha lainnya, serta kurang memasyarakatnya informasi tentang praktek-praktek berkoperasi yang benar (best practices) telah menyebabkan rendahnya kualitas kelembagaan dan organisasi koperasi. Bersamaan dengan masalah tersebut, koperasi dan UMKM juga menghadapi tantangan terutama yang ditimbulkan oleh pesatnya perkembangan globalisasi ekonomi dan liberalisasi perdagangan bersamaan dengan cepatnya tingkat kemajuan teknologi.

Bank memberikan pelayanan sesuai dengan kebutuhan debitur, Debitur senang terhadap pelayanan yang diberikan bank, Bank memberikan kesesuaian harapan yang diinginkan bank, Harapan yang dinginkan debitur dalam proses pinjaman sudah sesuai, Fasilitas yang diberikan bank dapat memberikan rasa kepuasan kepada Debitur, Fasilitas yang diberikan bank memberikan kenyaman kepeda 
debitur, Debitur merasa senang karena adanya pemberian reward bagi debitur yang tidak bermasalah, Pemberian reward memacu semangat debitur, Bank memberikan suku bunga yang bersaing dan Bank memberikan suku bunga sesuai dengan kemampuan debitur dalam proses pembayaran.

\section{Kesimpulan}

Hasil penelitian untuk variabel Sebelum Pemberian Kredit $\left(\mathrm{X}_{1}\right)$ diketahui Ho ditolak sedangkan $\mathrm{H}_{1}$ diterima, artinya dengan sesudah pemberian Kredit Mikro Sumut Sejahtera II maka perkembangan bisnis UMKM berkembang. Artinya dengan pemberian Kredit Mikro Sumut Sejahtera II maka perkembangan bisnis UMKM semakin meningkat dan meningkatkan jumlah pelanggan yang sedang berbelanja di Simpang Kwala Medan.

\section{REFERENSI}

Arafat, Wilson. 2003 Manajemen Perbankan Indonesia; Teori dan Implemntasi. Jakarta : LP3ES.

Behjati,et al.2012. Interrelation between Eservice Quality and E-satisfaction andLoyalty. Journal European Journal of Business and Management Vol 4, No.9.
Ghozali, Imam. 2006. Aplikai Analisis Multivarite dengan SPSS, Cetakan. Keempat, Badan Penerbit Universitas Diponegoro. Semarang.

Griffin,2005..Customer Loyalty :Loyalty is defined as non random purchase expressed overtime by some decision making unit.

Hafeez et al. 2012.The Impact Of Service Quality, Customer Satisfaction and Loyalty Programs on Customer's Loyalty: Evidence from Banking Sector of Pakistan, International Journal of Business and Social Science Vol. 3 No. Kuncoro Mudrajad. 2003. Metode Riset untuk Bisnis dan Ekonomi: Bagaimana Meneliti dan Menulis Tesis?, Penerbit: Erlangga, Jakarta.

Mokhtar et al.2011.The Relationship Between Service Quality and Satisfactionon Customer Loyalty in Malaysian Mobile

CommunicationIndustry. Journal

School of Doctoral Studies European Union.

Omboi dan Wangai. 2011. Factors that Influence the Demand for Credit for Credit Among Small-Scale Investors: a case study of Meru Central District, Kenya. Research Journal of Finance and Accounting www.iiste.org ISSN 22221697 (Paper) ISSN 2222-2847 (Online) Vol 2, No 2, 2011. 
Schiffman, Leon G. dan Lesli Lazar Kanuk. 2000. Consumer Behavior, $7^{\text {th }}$ Edition. Prentice Hall Inc, New Jersey: Upper Saddle River.

Sivesan. 2012. Service Quality and Customer Satisfaction: A Case Ctudy Banking Sectors in Jaffna District, Sri lanka. International Journal of Marketing, Financial Services \& Management Research. Vol.1 Issue 10, October 2012.

Sugiyono. 2006. Metode Penelitian Bisnis. Cetakan Keenam. Bandung: Alfabeta.

Stanton.2002. Pengantar Bisnis. Bandung: Alfabeta.

Suryana. 2001. Kewirausahaan. Salemba Empat, Jakarta.

Tjiptono, Fandy dan Anastasia Diana. 2008. Edisi Ke-lima. Total Quality Management (TQM). Yogyakarta : ANDI.

Wiloejo, Wijono. 2005. Mengungkap Sumber-sumber Pertumbuhan Ekonomi Indonesia dalam Lima Tahun Terakhir. Jurnal Manajemen dan Fiskal Volume V Nomor 2.

Biodata Penulis

Bunga Aditi, memperoleh gelar Sarjana Ekonomi (SE), Jurusan Manajemen Sekolah Tinggi Ilmu Ekonomi Harapan, lulus tahun 2011. Memperoleh gelar Magister Science (MSi) Program Pasca
Sarjana Magister Ilmu Manajemen Universitas Sumatera Utara, lulus tahun 2013. Saat ini menjadi Dosen tetap Program Studi Manajemen di Sekolah Tinggi Ilmu Ekonomi Harapan Medan

\&

